\title{
Flexible paddle sheds new light on speed: a novel method for the remote measurement of swim speed in aquatic animals
}

\author{
Emily L. C. Shepard ${ }^{1, *}$, Rory P. Wilson ${ }^{1}$, Nikolai Liebsch ${ }^{1}$, Flavio Quintana ${ }^{2,3}$, \\ Agustina Gómez Laich ${ }^{2}$, Klaus Lucke ${ }^{4}$ \\ ${ }^{1}$ Biological Sciences, Institute of Environmental Sustainability, University of Wales, Swansea SA2 8PP, UK \\ ${ }^{2}$ Centro Nacional Patagónico (CENPAT)-CONICET, (9120) Puerto Madryn, Chubut, Argentina \\ ${ }^{3}$ Wildlife Conservation Society, 2300 Southern Boulevard, New York, New York 10460, USA \\ ${ }^{4}$ Forschungs- und Technologiezentrum Westküste, Hafentörn, 25761 Büsum, Germany
}

\begin{abstract}
Speed is a key determinant of energy expenditure in free-living animals, and particularly in marine vertebrates, where power requirements for swimming increase as a cubed function of the speed. However, current devices used to measure swim speed in free-living animals have limitations, including excessive drag, low resolution, high stall speed (ca. $0.3 \mathrm{~m} \mathrm{~s}^{-1}$ ), cost, biofouling and susceptibility to damage. We present a speed sensor system that utilises the reflectance of infrared light against a flexible paddle that bends in relation to the flow of water over the study animal. In laboratory trials, this performed well across a range of speeds ( 0.1 to $\left.1.75 \mathrm{~m} \mathrm{~s}^{-1}\right)$, and had a stall speed of $0.1 \mathrm{~m} \mathrm{~s}^{-1}$. The advantages of this present paddle system are that it is impervious to the presence of matter in the water column, is inexpensive and easily replaceable. Furthermore, the system is able to record speed data at an unparalleled resolution, limited solely by sampling frequency. Data from deployments of devices on free-living imperial cormorants Phalacrocorax atriceps identified changes in speed within and between swim strokes, and also showed that greater speed was generated per kick as the buoyancy decreased with depth. As such, the flexible paddle system holds promise for the measurement of speed in free-living, aquatic animals.
\end{abstract}

KEY WORDS: Speed · Dive behaviour $\cdot$ Electronic tagging $\cdot$ Marine predator $\cdot$ Energy expenditure · Flow meter Resale or republication not permitted without written consent of the publisher

\section{INTRODUCTION}

The speed of movement is a key determinant of energy expenditure in swimming animals, as drag, which must be overcome in order to move, increases as an accelerating function of speed (Williams \& Kooyman 1985, Boyd et al. 1995). Consequently, high swim speeds are energetically costly (Feldkamp 1987) and there is strong selective pressure for animals to optimize locomotion over large- and small-scale movement (e.g. Thompson \& Hiby 1993, Wilson et al. 2002). The latter is particularly pertinent for air-breathers, for which the rate of energy expenditure is linked to time available underwater, and therefore, the depths that can be exploited in the water column, ultimately modulating foraging efficiency (Wilson \& Quintana 2004). This is also of importance in species of conservation concern, where an effective understanding of their ecology is required for their management. For marine vertebrates, this often involves the instrumentation of individuals to measure behavioural parameters, with speed being a key variable.

Despite huge advances in animal-attached recording technology (see Ropert-Coudert \& Wilson 2005 for 
review), the measurement of swim speed in free-ranging animals is still problematic in terms of the performance of transducers and their effects on instrumented animals. The most widely used speed sensors incorporate a propeller or turbine wheel that is rotated by ambient water flow (e.g. Ponganis et al. 1990, Sundström \& Gruber 1998, Ropert-Coudert et al. 2001, Sato et al. 2007). Speed is calibrated against the rotation rate (Ponganis et al. 1990, Wilson et al. 1992, Fletcher et al. 1996, Crocker et al. 2001, Eckert 2002). However, turbine-type systems can produce a non-uniform response to increasing speed (cf. Wilson \& Achleitner 1985), leading to a break-down in the relationship between rotations vs. distance travelled. Similarly, an analogous system, which is based on the rotations of a paddle wheel (e.g. Ponganis et al. 1990, Wilson et al. 1993), may lead to a reversal in wheel turning at high speeds due to variation in boundary turbulence with speed (R. P. Wilson unpubl. data). Another problem is that the performance of these mechanical systems can be compromised if debris becomes caught in the rotation body, limiting its life-span (Sundström \& Gruber 1998, Kreye 2003).

In addition, systems able to record high speeds can have correspondingly high stall speeds, typically 0.3 to $0.5 \mathrm{~m} \mathrm{~s}^{-1}$ (Sato et al. 2003, but see also Boyd et al. 1995, Eckert 2002 and Hassrick et al. 2007). In an effort to reduce this artefact, speed sensors based on the Prandl tube system (Kreye 2003) or a paddle linked to a secondary pressure sensor were developed and tested on free-ranging Magellanic penguins (Wilson et al. 2004). Whilst the former had a stall speed of $<0.1 \mathrm{~m} \mathrm{~s}^{-1}$, both systems were prone to mechanical failure (Kreye 2003).

Many sensitive speed transducers need to be covered in protective housing (Wilson et al. 2004), which increases the size and drag associated with the device. Minimal drag is critical in marine vertebrates (Bannasch et al. 1994), and increased drag from attached biotelemetry devices has been shown to affect animal behaviour and swimming and diving performance (Wilson et al. 1986, 2004, Ropert-Coudert et al. 2006).

We present a new method to measure speed, based on a flexible arm (hereafter referred to as a paddle) which bends back over an infrared (IR) emitter and sensor in relation to the rate of water flow over the device. Noting that the paddle bent increasingly with increasing speed, we postulated that greater water pressure against the paddle would cause an increase in IR reflectance. The performance of this system was tested in a swim channel across a range of known speeds in order to test the sensitivity of the system with variable paddle dimensions. Devices were also deployed on free-living imperial cormorants Phalacrocorax atriceps in order to test the effects on instrumented birds and its performance on free-swimming animals.

\section{MATERIALS AND METHODS}

Speed sensor system. An IR-emitting light-emitting diode was embedded in the Daily Diary data logger (Wilson et al. 2008; this Theme Section) adjacent to an IR sensor. A custom-made flexible paddle (see below) was fitted onto the device so that it stood perpendicular to the data logger when stationary (Fig. 1) and was forced back over the IR emitter/sensor as the study animal moved through the water (Fig. 1). It is worth noting that the paddle was stable in the upright position, only being bent closer to the IR sensor by an external force. As ambient IR wavelengths are absorbed in the first few $\mathrm{mm}$ of the water column (Williams 1970), fluctuations in levels of IR recorded by the device below this depth will be the result of changes in levels of deviceemitted, paddle-reflected IR, with IR levels tending to increase with increasing animal speed. Reflected IR readings were recorded in $\mathrm{mV}$.

The speed paddles were made from Silastic $\mathrm{P} 1{ }^{\circledR}$, a 2 part silicone-based rubber (Dow Corning Corporation, MI, USA; UK supplier: W. P. Notcutt, Ripley). Silicon oil was added at $10 \%$ of the silastic P1 base and catalyst mix to increase the elasticity of the final product. All paddles were made by pouring the silastic mix into a mould and cutting paddles to the desired length and width once the silastic set (see Fig. 1c for paddle dimensions). Paddle thickness remained constant at $2.5 \mathrm{~mm}$.

The paddle was attached to the upper surface of the data logger using TESA tape (Beiersdorf). An IR pass filter was set above the IR sensor in order to exclude wavelengths $>685 \mathrm{~nm}$ (Baader filters). A window was cut in the base of the paddle over the position of the IR sensor and filter. Relative values of IR were recorded using electronic data recorders that also logged triaxial

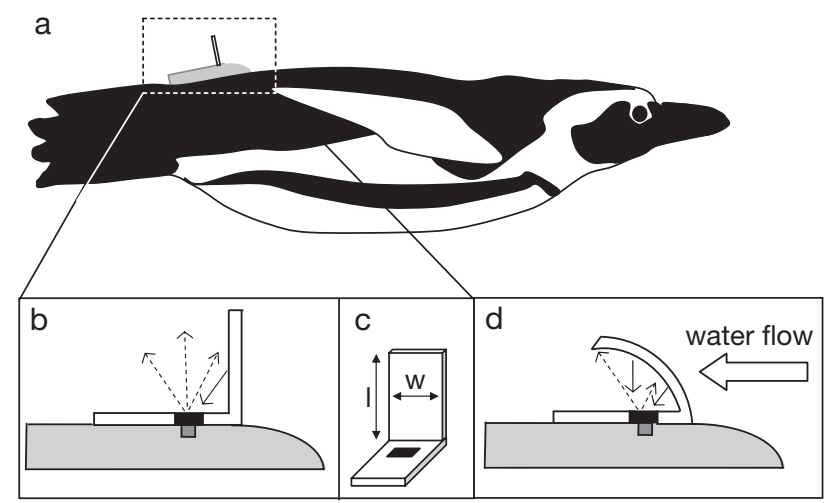

Fig. 1. (a) Attachment of device to model penguin, (b) a profile aspect of the paddle, with the infrared emitter and sensor (small dark grey box), beneath the infrared pass filter (black box), (c) paddle dimensions and (d) the bend in the silastic paddle due to water flow, increasing the reflectance to the IR sensor 
acceleration $(\mathrm{G})$, pressure (millibar) and sensor temperature $\left({ }^{\circ} \mathrm{C}\right)$ with 22 bit resolution in a $128 \mathrm{Mb}$ flash RA memory (Wilson et al. 2008). Electronic data loggers consisted of resin-potted daily diaries (Wilson et al. 2008), hydrodynamically shaped (cf. Bannasch et al. 1994) weighing $42 \mathrm{~g}$, with maximum dimensions of 55 $\times 30 \times 15 \mathrm{~mm}$. The loggers were programmed to record all parameters at $8 \mathrm{~Hz}$ using Terminal freeware.

Laboratory trials. In order to determine how paddles of different length and width responded across a range of known speeds, a data logger was attached to a fibreglass Spheniscus demersus penguin (made from a cast of a dead individual with a body mass of $3.7 \mathrm{~kg}$ ) and tested in a swim channel $(20 \times 1 \times 1 \mathrm{~m}$, see Wilson et al. 2004 for further details). The model penguin was suspended in the swim channel from a pulley system that could be programmed to move along the channel at 0.1 to $2 \mathrm{~m} \mathrm{~s}^{-1}$.

Two sets of trials were undertaken to test the effects of paddle length and width on the measurement of speed. Each paddle length and width was tested at 7 or 8 speeds starting at 0.1 or $0.25 \mathrm{~m} \mathrm{~s}^{-1}$, increasing in $0.25 \mathrm{~m} \mathrm{~s}^{-1}$ increments thereafter. Because we could not confirm that the model penguin achieved its programmed speed, speed was estimated in each trial using the time taken for the model to transit a $2 \mathrm{~m}$ section of the channel. The mean for each speed test was used in subsequent analyses. Only 1 paddle was tested twice across the full range of speeds, as the utility of these trials was compromised by inaccuracies surrounding the actual speed. We first tested the largest paddle (Table 1), before subsequently cutting it to the appropriate length for the next trial, in order to keep other variables constant, such as the position of the logger on the model. The data logger was attached to the model using TESA tape.

Field trials. Field trials were conducted in December 2006 at Punta León $\left(43^{\circ} 04^{\prime} \mathrm{S}, 64^{\circ} 2^{\prime} \mathrm{W}\right)$, Chubut,

Table 1. Dimensions of each paddle, along with mean infrared (IR) values at speeds of $0.1,0.25$ and $0.5 \mathrm{~m} \mathrm{~s}^{-1}$, where IR values could be resolved from the baseline

\begin{tabular}{|lcccc|}
\hline \multirow{2}{*}{$\begin{array}{l}\text { Length } \\
(\mathrm{mm})\end{array}$} & $\begin{array}{l}\text { Width } \\
(\mathrm{mm})\end{array}$ & $0.1 \mathrm{~m} \mathrm{~s}^{-1}$ & $0.25 \mathrm{~m} \mathrm{~s}^{-1}$ & $0.5 \mathrm{~m} \mathrm{~s}^{-1}$ \\
\cline { 3 - 5 } & & - & - & - \\
50 & 15 & 13 & 58 & 342 \\
45 & 15 & 102 & 93 & 381 \\
40 & 15 & 45 & 53 & 207 \\
35 & 15 & 11 & 15 & 72 \\
30 & 15 & 3 & 23 & 44 \\
25 & 15 & - & 19 & 21 \\
20 & 15 & 1 & - & 81 \\
30 & 30 & 3 & 6 & 13 \\
30 & 20 & 0 & 3 & 46 \\
30 & 10 & & & \\
30 & 5 & & & \\
\hline
\end{tabular}

Argentina, where 11 imperial cormorants Phalacrocorax atriceps were equipped with data loggers with paddles of dimensions $31 \times 16 \times 3 \mathrm{~mm}$. The cormorants were caught using a specially designed crook, which was used to remove them slowly from the nest. The fitting procedure took less than $5 \mathrm{~min}$, after which the birds were immediately returned to the nest where they continued brooding. Loggers were attached to the cormorants dorsally, ca. $2 \mathrm{~cm}$ from the origin of the tail feathers with TESA tape (Wilson et al. 1997). We attempted to keep the position of the logger constant among individuals. All cormorants fitted with devices were brooding small chicks. The birds were allowed to forage for a single trip before the devices were retrieved.

Data analysis. Data were downloaded from the devices prior to analysis using Origin Pro and Microsoft Excel software. IR values from each run of the swim channel were averaged to give mean IR and standard deviation per speed per paddle.

\section{RESULTS}

\section{Laboratory trials}

Our paddle system produced reliable measurements in relation to speed of locomotion. A large decrease in IR readings to a stable baseline (see below) occurred upon submersion of the device, confirming that IR was eliminated from the ambient light. Temperature equilibration was found to affect the IR sensor. When devices were submerged following extended periods at room temperature, it took $7 \mathrm{~min}$ for IR levels to stabilizethe time needed for the device to equilibrate with water temperature $\left(13^{\circ} \mathrm{C}\right)$. This produced shifts in baseline IR values as the sensor temperature changed to accord to that of the water. In order to standardize IR values across trials, we subtracted IR values from periods of movement from a baseline value, calculated as the mean value over the $4 \mathrm{~s}$ preceding the trial. Whilst no changes in the IR baseline were observed when the logger was out of the water for periods of up to $1.5 \mathrm{~min}$, the IR values for the 0.1 and $0.25 \mathrm{~m} \mathrm{~s}^{-1}$ trials could not be resolved for paddles with dimensions of $30 \times 30 \times$ $2.5 \mathrm{~mm}$ and $50 \times 15 \times 2.5 \mathrm{~mm}$ due to changes in the IR baseline.

The paddle system proved highly sensitive to increases in speed, with all paddles resolving movement of the test model at $0.25 \mathrm{~m} \mathrm{~s}^{-1}$. During trials, there was a change in paddle orientation at a speed of $0.1 \mathrm{~m}$ $\mathrm{s}^{-1}$; however, this could only distinguish movement in paddles of 35, 40 and $45 \mathrm{~mm}$ length (see Table 1 for IR values). IR reflectance increased with speed up to the maximum programmable level $\left(2 \mathrm{~m} \mathrm{~s}^{-1}\right)$, with one 
anomalous result where a length of $40 \mathrm{~mm}$ gave a higher IR value for 0.1 than $0.25 \mathrm{~m} \mathrm{~s}^{-1}$. The system also registered a reversal of the model penguin, with IR values decreasing below the baseline level following completion of each run (Fig. 2).

Two consecutive trials with the same paddle produced consistent results (Fig. 3), though the absolute accuracy of the system between 2 adjacent runs could not be assessed due to inaccuracies in programmable speeds. Two patterns of variance were apparent within speed categories. Firstly, an increase in IR was observed within one trial (Fig. 2), which is likely to reflect the acceleration of the model penguin towards the target speed and may account for the general trend of increasing variance with speed across all paddle sizes. In addition, regular fluctuations with a period of around $2 \mathrm{~s}$ were observed after several trials had been conducted (Fig. 2). This appeared to be in response to standing waves generated in the channel by move-

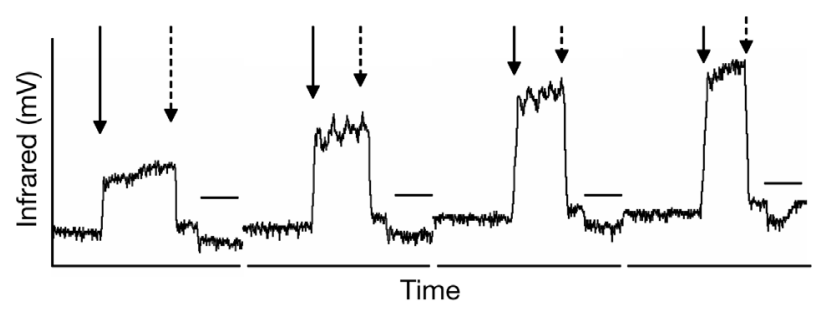

Fig. 2. Infrared reflectance in 4 successive speed trials $(0.75$, $1,1.25$ and $1.5 \mathrm{~m} \mathrm{~s}^{-1}$ ). Acceleration from zero to the trial speed induces a sudden increase in infrared reflectance (solid arrows), this being reversed at the end of each trial (dashed arrows). Decrease in baseline values corresponds to the paddle being bent in the opposite direction as the model is reversed to the start position (horizontal lines). A paddle length of $31 \mathrm{~mm}$ and width $16 \mathrm{~mm}$ was used in all trials

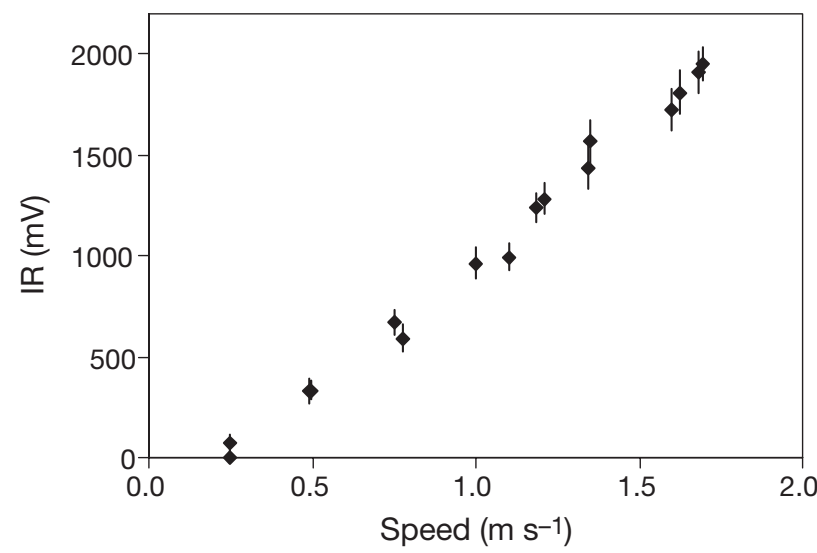

Fig. 3. Relationship between the mean estimated speed and infrared (IR) reflectance $( \pm \mathrm{SD})$ for a device attached to a model penguin tested in the swim channel ment of the model/pulley system. A further possible source of variance was a high frequency rippling in the end of the paddles, observed at speeds $>0.75$ to $1 \mathrm{~m} \mathrm{~s}^{-1}$ in paddles $>30 \mathrm{~mm}$ in length, and at 30 or $5 \mathrm{~mm}$ width. Once rippling began, its amplitude did not increase with speed, but did appear to increase with increasing paddle length.

Increasing paddle length caused a number of changes in the relationship between IR and speed (Fig. 4a). As paddle length increased from 20 to $40 \mathrm{~mm}$, the slope of IR against speed became steeper (Fig. 4a). However, above $40 \mathrm{~mm}$ the slope decreased. Furthermore, as paddle length increased, the IR speed curve appeared to shift left, with IR values starting to plateaux at higher speeds. As paddle length increased from 40 to $50 \mathrm{~mm}$, the IR values plateaued at lower speeds (Fig. 4), indicating a reduction in both sensitivity and the range of measurable speeds for paddles $>40 \mathrm{~mm}$ in length.

Increasing paddle width from 5 to $20 \mathrm{~mm}$ caused slight increases in the sensitivity of the paddle (Fig. 4b, Table 1), and a major increase when width increased from 20 to $30 \mathrm{~mm}$. This was also accompanied by a 3.5fold increase in variance as speeds increased above $1 \mathrm{~m} \mathrm{~s}^{-1}$.
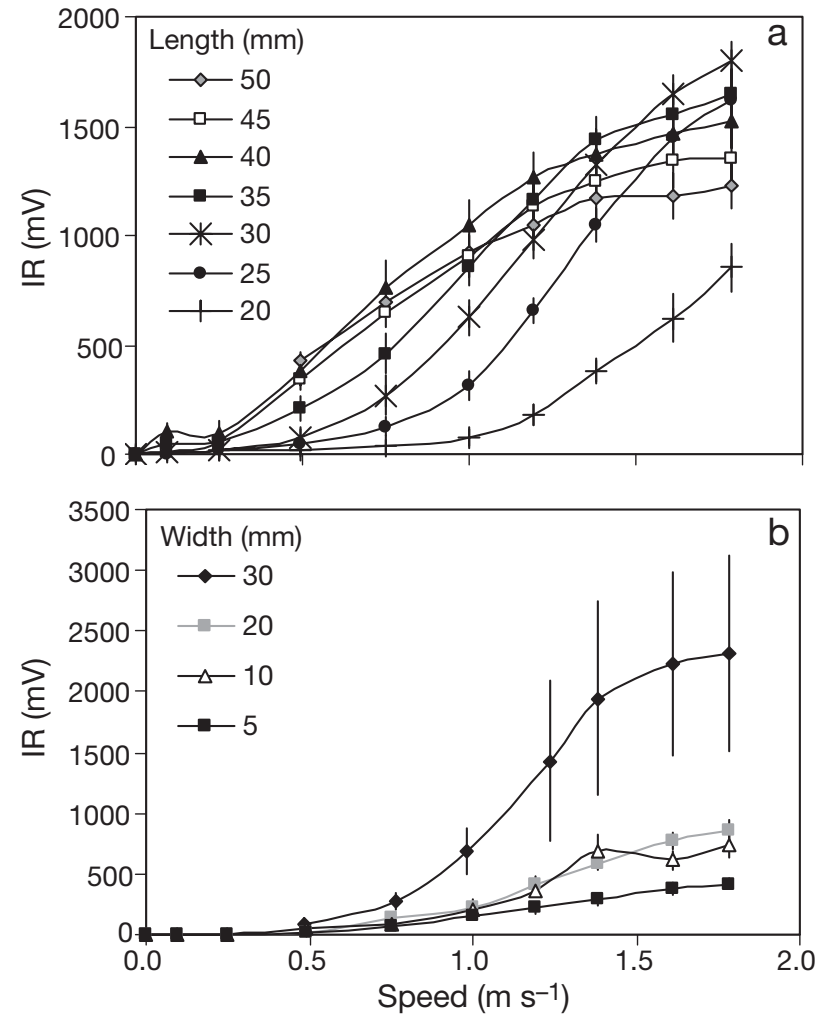

Fig. 4. (a) Relationship between measured speed and infrared $(\mathrm{IR})$ reflectance $( \pm \mathrm{SD})$ for trials where paddle (a) length and (b) width was varied 
Interestingly, a $30 \times 15 \times 2.5 \mathrm{~mm}$ paddle (used in the 1 st set of trials), produced proportionately higher IR values than paddles of $30 \times 20 \times 2.5 \mathrm{~mm}$ and $30 \times 10 \times$ $2.5 \mathrm{~mm}$ in later trials. This could be due to either the position of the device, which was re-attached to the model bird before 'width' trials commenced, or a change in the distance from the IR pass filter and IR emitter/sensor to the paddle when a new paddle was attached.

\section{Field trials}

All cormorants fitted with devices returned to the colony with no apparent ill effects from device deployment. All paddles remained intact and in the same position on the loggers, although there was a small indentation on one paddle consistent with a beak mark.

In field deployments, the speed sensor was capable of differentiating changes in speed within dives (Fig. 5), including a general reduction in speed as the cormorant started to move along the sea-floor, and an increase in the bottom phase concomitant with an increase in dynamic heave acceleration corresponding to forward propulsive kicks (Wilson et al. 2008). Within the descent, changes in speed were apparent over periods of $0.25 \mathrm{~s}$ (Fig. 5), concurrent with peaks in heave acceleration, most likely resulting from individual kicks. The trace shows that as the bird descended, propulsive kicks became less frequent. Interestingly, whilst the heave resulting from each kick remained similar in the first $20 \mathrm{~m}$ of descent, the speed generated per kick increased.

\section{DISCUSSION}

The present system offers several practical benefits for the measurement of speed in free-ranging animals. There is no need to protect the system in housing, which minimises the size and drag of the system and enables deployment on smaller species. Secondly, the paddle is made from lightweight material (total paddle mass for field trials was typically $<4 \mathrm{~g}$ ), which may be an advantage for deployment on species, such as cormorants, that also use flight. Being flexible, the paddle is unlikely to be torn or snapped, and consequently should be able to withstand contact with hard substrates, investigation by the study animal and debris in the water column. If the paddle is damaged or lost, it is easily replaceable upon retrieval of the device. As such, this system is a potentially economical way to measure speed over extended time periods. It could also be adapted for use as a flow meter. These are used
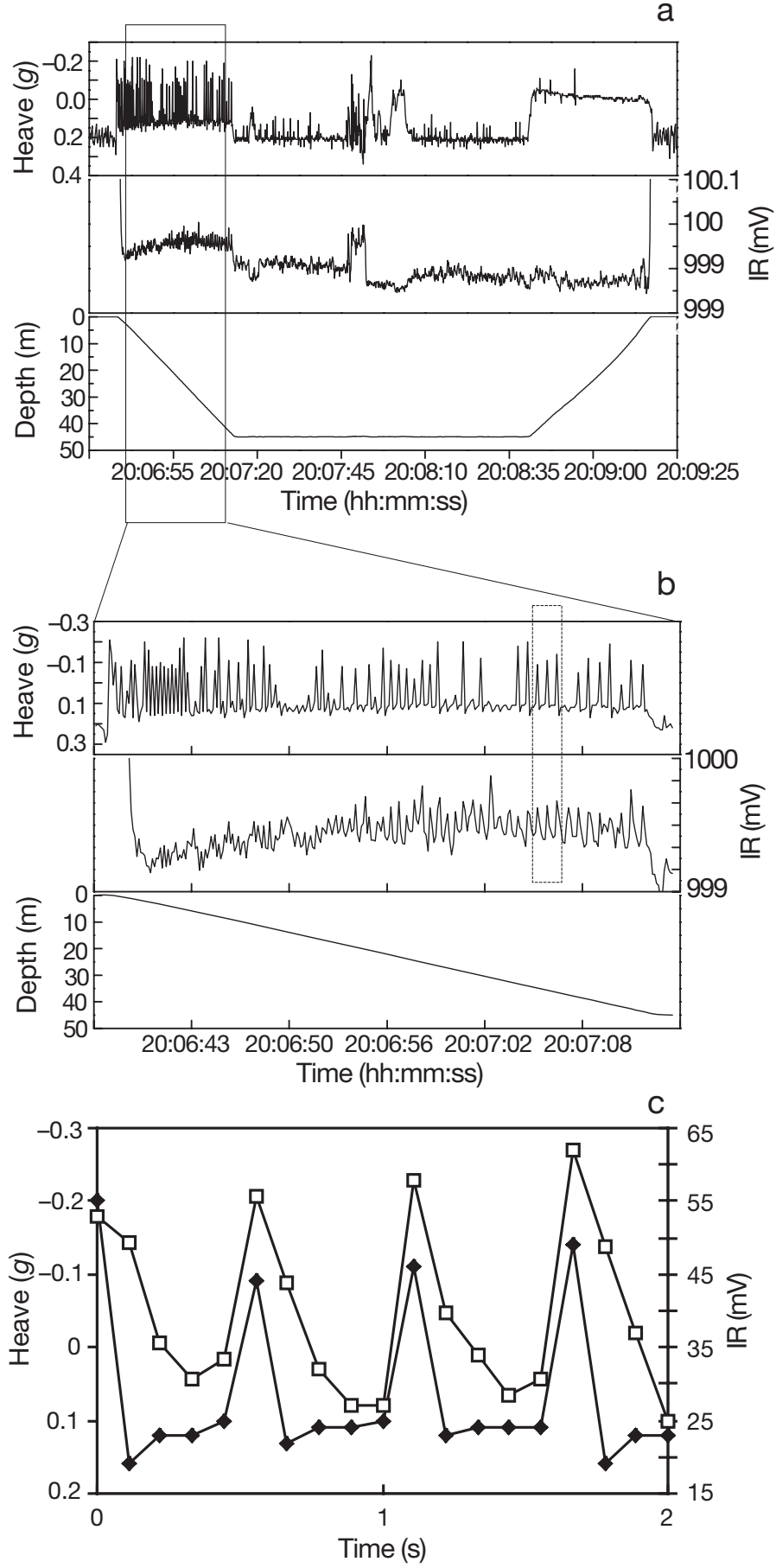

Fig. 5. Phalacrocorax atriceps. (a) Changes in heave, IR and depth for a single dive of imperial cormorants. (b) Descent, with speed changes corresponding to kicks, apparent in the heave axis, as the bird descended. Not all kicks were registered in the heave axis due to the high kick frequency (up to $5 \mathrm{~Hz}$ ) and the correspondingly short peak in heave values. Kicks are more reliably recorded as increases in speed, which decrease slowly after the initial, rapid increase. (c) Heave $(\diamond)$ and infrared $(I R, \square)$ for 3 kicks in the descent phase (as indicated in panel b), demonstrating the coupling of speed with heave acceleration at a fine scale, and the exponential decay of speed following the power stroke 
widely, for instance to record the flow through plankton sampling nets, yet are also subject to clogging (John et al. 2002).

This paddle system performed well when attached to the model bird in the swim channel, with IR reflectance increasing with speed up to a maximum of $2 \mathrm{~m} \mathrm{~s}^{-1}-\mathrm{a}$ range that includes the mean speed of movement across air-breathing marine predators (Sato et al. 2007). Its performance was confirmed in field deployments, where increases in IR corresponded with increases in acceleration over time spans from $125 \mathrm{~ms}$ to the entire dive cycle (Fig. 5). As expected, laboratory trials were not able to provide an absolute calibration of IR reflectance against speed, due to the differences in drag between the model and living birds, and the effects of the swim channel walls and pulley system on the flow of water over the model (Culik et al. 1994, Wilson et al. 2004). Consequently, all devices require calibration of IR reflectance per field deployment (Watanuki et al. 2003). This also mitigates against variation in paddle performance due to differences in device placement on the study organism.

The low stall speed of the device suggests that it holds promise for the measurement of speed in slowmoving marine animals. It is likely that the stall speed could be reduced further by adjusting paddle elasticity, orientation, or the distance from the IR sensor/ emitter to the paddle. Animals, such as smaller species of turtles, have not yet been equipped with speed sensors, in part due to the mismatch between their travel speeds and the range of speeds measurable by other sensors. Some paddles in the present study (e.g. 35, 40 and $45 \mathrm{~mm}$ length) combined a low stall speed with the ability to differentiate between the full range of tested speeds. The relationship between IR reflectance and speed was curvilinear, and thus by changing the paddle dimensions it is possible to adjust the range of speeds over which the paddle is most sensitive. Although increasing the length of the paddle initially (from 20 to $40 \mathrm{~mm}$ ) resulted in greater sensitivity at lower speeds, paddles $>40 \mathrm{~mm}$ led to a decline in sensitivity at higher speeds. Thus, in order to adjust the sensitivity of the paddle to different anticipated speeds, it would be more effective to alter paddle length than width, because alterations in width from 5 to $20 \mathrm{~mm}$ did not produce as great a change in IR values as varying paddle length across this range. A large width $(30 \mathrm{~mm})$ caused visible wobbling of the paddle at speeds $>1.25 \mathrm{~m} \mathrm{~s}^{-1}$, generating highly variable IR values in this range.

The system also resolved changes in speed at a fine temporal resolution, apparently only limited by the sampling frequency. This is in contrast to propellerbased systems, which calibrate speed with the number of rotations per unit time, and thereby average varia- tion in speed that might occur within one rotation. Whilst this does not pose a general problem, as diving animals should travel at relatively constant speeds that accord with their minimum cost of transport (Culik et al. 1991), it is not effective during short bursts of acceleration (such as that which occurs during prey capture in some penguins; Wilson et al. 2002). A benefit of the proposed paddle system may therefore lie in its ability to resolve fine-scale changes in speed. Such variation was evident in the descent of an imperial cormorant equipped in the field. As depth increases, buoyancy decreases, resulting in greater down-thrust per kick, as has recently been demonstrated in imperial cormorants (Quintana et al. 2007). In the present study, we showed the range of speeds that birds experience during oscillatory strokes, and further, that birds experience an increase in speed per kick in the first 20 to $30 \mathrm{~m}$ of descent (e.g. Fig. 5). The reduction in velocity evident at the end of the power stroke suggests that these data could be used to calculate the drag coefficient $\left(C_{\mathrm{D}}\right)$ of the study organism using the deceleration method (Bilo \& Nachtigall 1980, Feldkamp 1987).

There are, however, apparent limitations to the present system. The resolution of the system is likely to be influenced by the resolution of the recording device (22 bit resolution in the present study), as the levels of IR in ambient light far exceed those produced by the IR sensor, fluctuations in IR resulting from the paddle occur in a small portion of the sensor's range. Devices with lower bit resolution may therefore be unable to resolve fine-scale changes in speed, though this may also be mitigated by minimising the distance between the IR sensor and the speed paddle.

Solid-state sensors, including our paddle device, typically have a response that varies with temperature. Accordingly, measurement of IR in the present study requires the development of a corrective algorithm before data collected in the field can be quantitatively explored, which is beyond the scope of the present study. Salinity and turbidity also affect the absorption and reflectance of IR (Pegau et al. 1997). This could potentially cause a shift in baseline IR values if an organism moves between water masses with different properties. However, such a shift should be evident on visual inspection of the data, and, in extreme scenarios, speed could be re-calibrated on a dive-by-dive basis.

There are some instances when the proposed system will be unable to measure speed. For instance, the device will only work when the speed paddle is orientated perpendicular to the study organism and the study animal is moving forwards. As southern elephant seals Mirounga leonina, for example, descend in part with their tails lower than their heads (Leboeuf et al. 1992), the proposed paddle system would not measure 
speed of descent, though calibration may be possible during the ascent.

In conclusion, a new method for the measurement of speed is presented that responded to speeds up to a tested maximum of $2 \mathrm{~m} \mathrm{~s}^{-1}$. The sensitivity of the system was adjustable to different target speed ranges, and had a minimum stall speed of $0.1 \mathrm{~m} \mathrm{~s}^{-1}$ with current paddle specifications (Table 1). The main advantages of this method are likely to be the physical flexibility of the paddle, combined with the potential to record speed at very high resolution. Such data will enable more accurate reconstruction of fine-scale behaviour, and may prove a powerful tool when coupled with other systems. For instance, dead-reckoning systems (Wilson et al. 1991) are currently the only means of fine-scale underwater track reconstruction (Wilson et al. 2007). Simultaneous deployment of a speed sensor with a dead-reckoner could increase the accuracy of fine-scale measurements and thereby minimise cumulative errors (Wilson et al. 1991). Furthermore, preliminary trials have shown overall dynamic body acceleration (ODBA) to correlate well with energy expenditure in both captive and free-living animals (Wilson et al. 2006). The deployment of speed sensors with accelerometers would therefore provide a means of calibrating speed against ODBA, enabling estimation of the energetic costs of swimming in freeliving animals. Such information on the energetic expenditure, and ultimately budgets, of free-living animals may provide important insights into some of the stresses faced by aquatic animals.

Acknowledgements. E.L.C.S. is funded by a NERC studentship. Device development was supported by a Rolex Award for Enterprise, awarded to R.P.W. We are grateful to Maud Coudert for her work with silastic. We also thank the Organismo Provincial de Turismo for the permits to work in Punta Leon, and the Centro Patagónico (CONICET) for institutional support. We thank Graeme Hays and 3 anonymous reviewers for their helpful comments on the manuscript.

\section{LITERATURE CITED}

Bannasch R, Wilson RP, Culik B (1994) Hydrodynamic aspects of design and attachment of a back-mounted device in penguins. J Exp Biol 194:83-96

Bilo D, Nachtigall W (1980) A simple method to determine drag coefficients in aquatic animals. J Exp Biol 87:357-359

Boyd IL, Reid K, Bevan RM (1995) Swimming speed and allocation of time during the dive cycle in Antarctic fur seals. Anim Behav 50:769-784

Crocker DE, Gales NJ, Costa DP (2001) Swimming speed and foraging strategies of New Zealand sea lions (Phocarctos hookeri). J Zool Lond 254:267-277

Culik BM, Wilson RP, Dannfeld R, Adelung D, Spairani HJ, Coria NRC (1991) Pygoscelid penguins in a swim canal. Polar Biol 11:277-282
Culik BM, Wilson RP, Bannasch R (1994) Underwater swimming at low energetic cost by pygoscelid penguins. J Exp Biol 197:65-78

Eckert SA (2002) Swim speed and movement patterns of gravid leatherback sea turtles (Dermochelys coriacea) at St Croix, US Virgin Islands. J Exp Biol 205:3689-3697

Feldkamp SD (1987) Swimming in the California sea lionmorphometrics, drag and energetics. J Exp Biol 131: 117-135

Fletcher S, LeBoeuf BJ, Costa DP, Tyack PL, Blackwell SB (1996) Onboard acoustic recording from diving northern elephant seals. J Acoust Soc Am 100:2531-2539

Hassrick JL, Crocker DE, Zeno RL, Blackwell SB, Costa DP, Le Boeuf BJ (2007) Swimming speed and foraging strategies of northern elephant seals. Deep-Sea Res II 54:369-383

John EH, Batten SD, Stevens D, Walne AW, Jonas T, Hays GC (2002) Continuous plankton records stand the test of time: evaluation of flow rates, clogging and the continuity of the CPR time-series. J Plankton Res 24:941-946

Kreye JM (2003) Messung der Schwimmgeschwindigkeit und deren Konsequenzen für luftatmende Marine Vetebraten. Diplom-Biologen, Universität des Saarlandes, Saarbrücken

Leboeuf BJ, Naito Y, Asaga T, Crocker D, Costa DP (1992) Swim speed in a female northern elephant seal-metabolic and foraging implications. Can J Zool 70:786-795

Pegau WS, Gray D, Zaneveld JRV (1997) Absorption and attenuation of visible and near-infrared light in water: dependence on temperature and salinity. Appl Optics 36: 6035-6046

Ponganis PJ, Ponganis EP, Ponganis KV, Kooyman GL, Gentry RL, Trillmich F (1990) Swimming velocities in otariids. Can J Zool 68:2105-2112

Quintana F, Wilson RP, Yorio P (2007) Dive depth and plumage air in wettable birds: the extraordinary case of the imperial cormorant. Mar Ecol Prog Ser 334:299-310

Ropert-Coudert Y, Wilson RP (2005) Trends and perspectives in animal-attached remote sensing. Front Ecol Environ 3: $437-444$

Ropert-Coudert Y, Kato A, Baudat J, Bost CA, Le Maho Y, Naito Y (2001) Feeding strategies of free-ranging Adelie penguins Pygoscelis adeliae analysed by multiple data recording. Polar Biol 24:460-466

Ropert-Coudert Y, Gremillet D, Kato A (2006) Swim speeds of free-ranging great cormorants. Mar Biol 149:415-422

Sato K, Mitani Y, Cameron MF, Siniff DB, Naito Y (2003) Factors affecting stroking patterns and body angle in diving Weddell seals under natural conditions. J Exp Biol 206: 1461-1470

Sato K, Watanuki Y, Takahashi A, Miller PJO and 14 others (2007) Stroke frequency, but not swimming speed, is related to body size in free-ranging seabirds, pinnipeds and cetaceans. Proc R Soc Lond B 274:471-477

Sundström LF, Gruber SH (1998) Using speed-sensing transmitters to construct a bioenergetic model for subadult Lemon sharks, Negaprion brevirostris (Poey) in the field. Hydrobiologia 371/372:241-247

Thompson D, Hiby AR (1993) How fast should I swim? Behavioural implications of diving physiology. In: Boyd IL (ed) Marine mammals: advances in behavioural and population biology. Clarendon Press, Oxford, p 349-368

Watanuki Y, Niizuma Y, Gabrielsen GW, Sato K, Naito Y (2003) Stroke and glide of wing-propelled divers: deep diving seabirds adjust surge frequency to buoyancy change with depth. Proc R Soc Lond B 270:483-488

Williams J (1970) Optical properties of the sea. United States Naval Institute, Annapolis, MD

Williams TM, Kooyman GL (1985) Swimming performance 
and hydrodynamic characteristics of harbor seals Phoca Vitulina. Physiol Zool 58:576-589

Wilson RP, Achleitner KD (1985) A distance meter for large swimming marine animals. S Afr J Mar Sci 3: 191-195

Wilson RP, Quintana F (2004) Surface pauses in relation to dive duration in imperial cormorants; how much time for a breather? J Exp Biol 207:1789-1796

Wilson RP, Grant WS, Duffy DC (1986) Recording devices on free-ranging marine animals-does measurement affect foraging performance? Ecology 67:1091-1093

Wilson RP, Wilson MP, Link R, Mempel $H$, Adams NJ (1991) Determination of movements of African penguins using a compass system: dead reckoning may be an alternative to telemetry. J Exp Biol 157:557-564

Wilson RP, Culik BM, Bannasch R, Driesen HH (1992) Monitoring penguins at sea using data loggers. In: Paolo $\mathrm{M}$, Sandro F, Cristina C, Remo B (eds) Biotelemetry XII. Litografia Felici, Pisa, p 205-214

Wilson RP, Puetz K, Bost CA, Culik BM, Bannasch R, Reins T, Adelung D (1993) Diel dive depth in penguins in relation to diel vertical migration of prey: whose din-

Editorial responsibility: Brendan Godley (Editor-in-Chief), University of Exeter, Cornwall Campus, UK ner by candlelight? Mar Ecol Prog Ser 94:101-104

Wilson RP, Putz K, Peters G, Bost CA, Culik B, Scolaro JA, Charrassin JB, Ropert-Coudert Y (1997) Long-term attachment of transmitting and recording devices to penguins and other seabirds. Wild Soc Bull 25:101-106

Wilson RP, Ropert-Coudert Y, Kato A (2002) Rush and grab strategies in foraging marine endotherms: the case for haste in penguins. Anim Behav 63:85-95

Wilson RP, Kreye JA, Lucke K, Urquhart H (2004) Antennae on transmitters on penguins: balancing energy budgets on the high wire. J Exp Biol 207:2649-2662

Wilson RP, White CR, Quintana F, Halsey LG, Liebsch N, Martin GR, Butler PJ (2006) Moving towards acceleration for estimates of activity-specific metabolic rate in free-living animals: the case of the cormorant. J Anim Ecol 75:1081-1090

Wilson RP, Liebsch N, Daviesc IM, Quintana F and 13 others (2007) All at sea with animal tracks; methodological and analytical solutions for the resolution of movement. DeepSea Res II 54:193-210

Wilson RP, Shepard ELC, Liebsch N (2008) Prying into the intimate details of animal lives: use of a daily diary on animals. Endang Species Res 4:123-137

Submitted: July 13, 2007; Accepted: August 30, 2007 Proofs received from author(s): October 2, 2007 